\title{
Has land subsidence changed the flood hazard potential? A case example from the Kujukuri Plain, Chiba Prefecture, Japan
}

\author{
H. L. Chen ${ }^{1}$, Y. Ito ${ }^{2}$, M. Sawamukai ${ }^{3}$, T. Su ${ }^{2}$, and T. Tokunaga ${ }^{2}$ \\ ${ }^{1}$ School of Environmental Science and Engineering, Zhejiang Gongshang University, Hangzhou, 310018, China \\ ${ }^{2}$ Department of Environment Systems, School of Frontier Sciences, The University of Tokyo, \\ Tokyo, 277-8563, Japan \\ ${ }^{3}$ VisionTech Inc., Tsukuba-city, Ibaraki, 305-0045, Japan \\ Correspondence to: H. L. Chen (hualichen57@126.com)
}

Published: 12 November 2015

\begin{abstract}
Coastal areas are subject to flood hazards because of their topographic features, social development and related human activities. The Kujukuri Plain, Chiba Prefecture, Japan, is located nearby the Tokyo metropolitan area and it faces to the Pacific Ocean. In the Kujukuri Plain, widespread occurrence of land subsidence has been caused by exploitation of groundwater, extraction of natural gas dissolved in brine, and natural consolidation of the Holocene and landfill deposits. The locations of land subsidence include areas near the coast, and it may increase the flood hazard potential. Hence, it is very important to evaluate flood hazard potential by taking into account the temporal change of land elevation caused by land subsidence, and to prepare hazard maps for protecting the surface environment and for developing an appropriate land-use plan. In this study, flood hazard assessments at three different times, i.e., 1970, 2004, and 2013 are implemented by using a flood hazard model based on Multicriteria Decision Analysis with Geographical Information System techniques. The model incorporates six factors: elevation, depression area, river system, ratio of impermeable area, detention ponds, and precipitation. Main data sources used are $10 \mathrm{~m}$ resolution topography data, airborne laser scanning data, leveling data, Landsat-TM data, two 1:30000 scale river watershed maps, and precipitation data from observation stations around the study area and Radar data. The hazard assessment maps for each time are obtained by using an algorithm that combines factors with weighted linear combinations. The assignment of the weight/rank values and their analysis are realized by the application of the Analytic Hierarchy Process method. This study is a preliminary work to investigate flood hazards on the Kujukuri Plain. A flood model will be developed to simulate more detailed change of the flood hazard influenced by land subsidence.
\end{abstract}

\section{Introduction}

Flooding in coastal areas is one of the most devastating natural hazards, which causes considerable property damage and personal injury (Doornkamp, 1998; Hunt and Watkiss, 2011). Different from other areas, coastal lowland areas can be influenced by both natural process and anthropogenic activities which make the area at higher risk of floods than others. At the same time, there is a growing awareness of anthropogenic impact and positive/negative feedbacks on flooding (IPCC, 2013). Rapid expansion in human settlements increases im- perviousness which in turn increases peak discharge and surface runoff. Widespread land subsidence caused by excessive groundwater withdrawal or engineering activities further amplifies the harmful effects of flooding by modifying the ground elevation, stream slopes and flow pathways. On the other hand, some activities such as construction of detention ponds can buffer the flow to reduce the risk of flooding. Factors related to flood hazards are changing in spatial and temporal scales which increase the difficulties of accurate flood hazard assessment. 


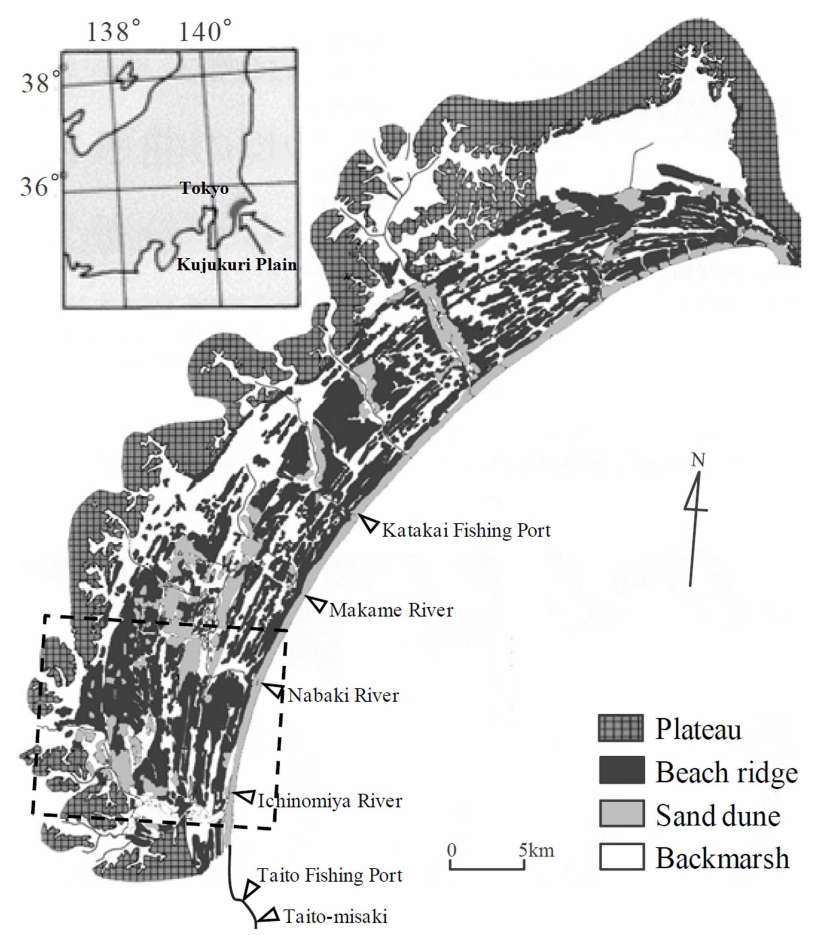

Figure 1. Geomorphological map of the Kujukuri Plain (Obanawa et al., 2010). Square marked by dashed line indicates the study area.

The Kujukuri Plain (Fig. 1), Chiba Prefecture, Japan, suffers from flood hazards. Many natural processes and anthropogenic activities have changed the surface environment of the Plain, such as agricultural development, urban and industrial development, change of drainage patterns, and deposition and/or erosion of river beds. Due to the exploitation of groundwater, extraction of natural gas dissolved in brine, and natural consolidation of the Holocene and landfill deposits, widespread land subsidence has occurred in the Plain (Environmental and Community Affairs Department, Chiba Prefecture 1970-2007). All of these factors could more or less increase the risk of flooding in the Kujukuri Plain. Therefore, constructing flood hazard potential maps for different periods is meaningful to study the change of the spatial and temporal patterns of the hazard potential for discussing future land-use planning of the Kujukuri Plain.

\section{Methodology}

A semi-quantitative method was selected to investigate the flood hazard assessment due to the scarcity of good quality data in the study area (Chen et al., 2015). Figure 2 shows the steps used in this study including data gathering, Geographic information system (GIS) manipulation, and Multicriteria Decision Analysis. The main data used are airborne laser scanning data, leveling data, Landsat-TM data, two river watershed maps with 1:30000 scale, and radar precipitation data. Based on these data, five layers expressing condition

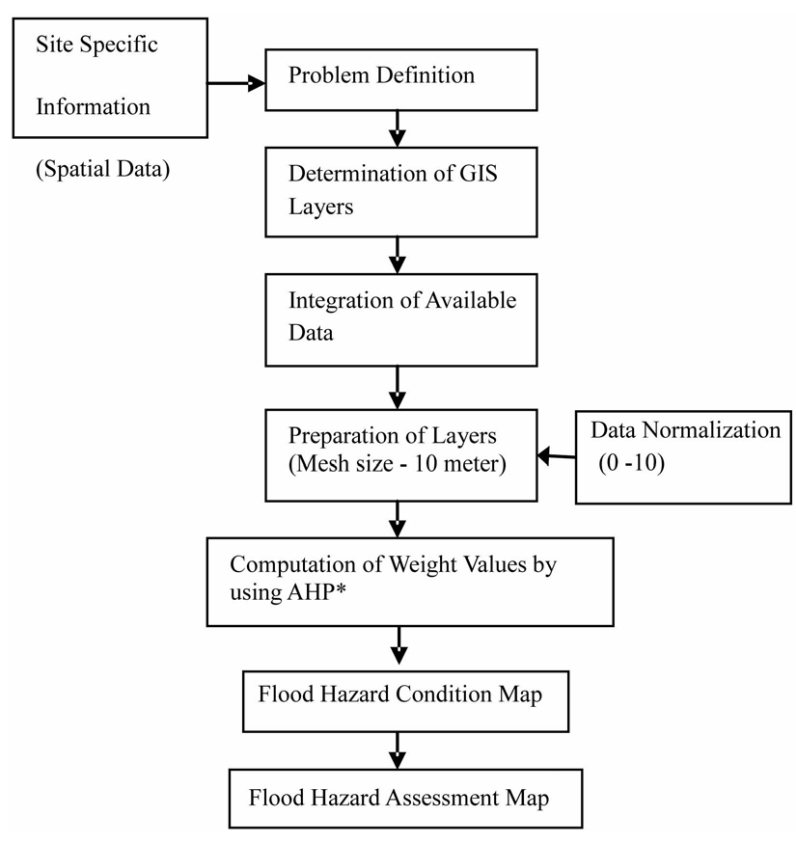

Figure 2. Flow chart for making the flood hazard map. * AHP Analytical Hierarchy Process.

factors were constructed, i.e., river system, elevation, depression area, ratio of impermeable area, and detention ponds. Precipitation was the main factor to trigger floods. A layer for the triggering factor, i.e., precipitation distribution, was created from radar precipitation data. The next step was to assign weights to each layer. The Analytic Hierarchy Process method (Saaty, 1980) was applied to assign the weight values (Table 1). The pixel value of the condition and assessment map was calculated by overlapping the factor layers.

\section{Analysis and results}

As shown in Fig. 3, each layer was created for three periods, i.e., year 1970, 2004 and 2013. The river system data for 2004 and 2013 were similar because no significant change was found between two periods. Data quality of year 1970 were not good compared with those of year 2004 and 2013, especially the elevation and the precipitation data. For detention ponds layer, there was no such structure for year 1970. So, the condition and assessment maps were calculated only for year 2004 and 2013 (Fig. 4). Here, the higher values indicate the higher likelihood of floods. In the flood hazard assessment map, the studied area was divided into five classes by using the quantiles method which created nearly equal ratios of the coverage in each class, i.e., very high, high, moderate, low, and very low hazards potential. The assessment map (Fig. 4) shows that the southeastern, the northeastern and the central parts of the study area are expected to have highest flood hazard potential as a consequence of the combination of high precipitation with lower elevation difference 

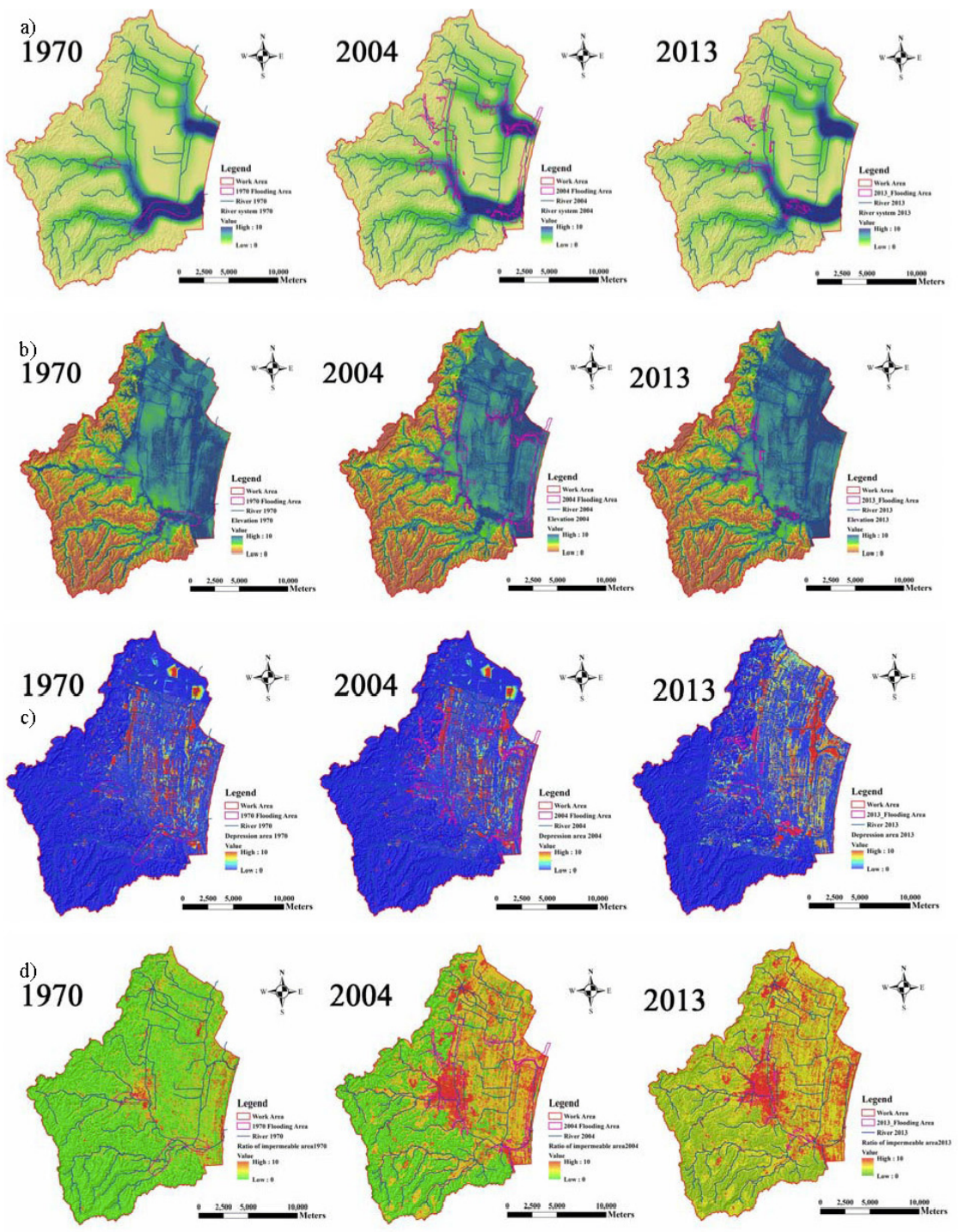

e)
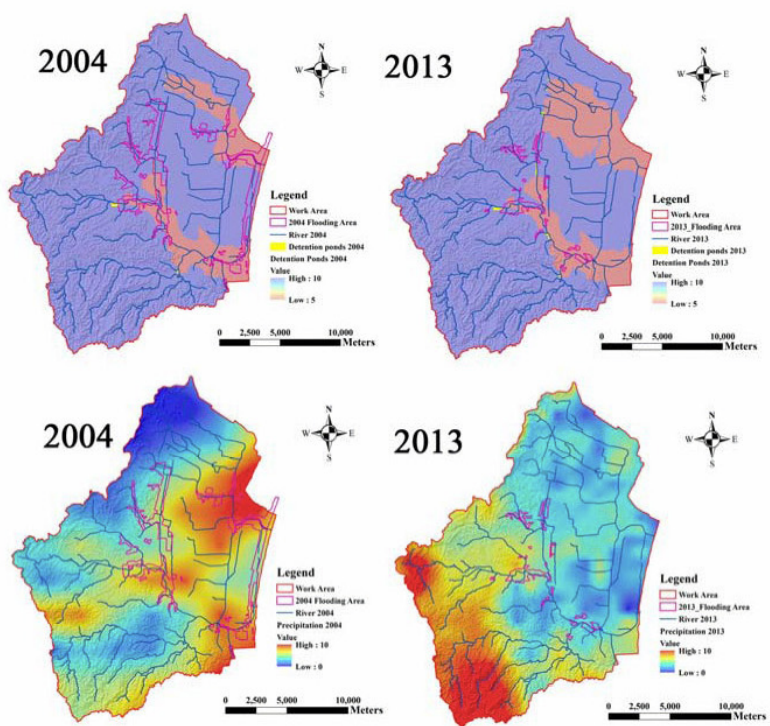

f)

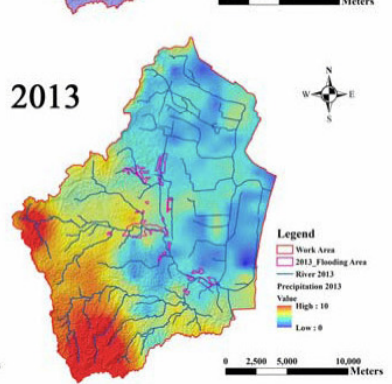

Figure 3. The images of each layer for the flood hazard assessment. The areas surrounded by pink line show the ones actually flooded. Figures in the left column are those for year 1970, the center for year 2004, and the right for year 2013. (a) River system layer, (b) elevation layer, (c) depression area layer, (d) ratio of impermeable area (Ratio of IA) layer, (e) detention ponds layer, and (f) precipitation layer. 
Table 1. Assigned weights for the layers.

\begin{tabular}{|c|c|c|c|c|c|c|c|}
\hline Layer & $\begin{array}{r}\text { River } \\
\text { system }\end{array}$ & Elevation & $\begin{array}{r}\text { Depression } \\
\text { area }\end{array}$ & $\begin{array}{r}\text { Ratio of } \\
\text { impermeable area }\end{array}$ & $\begin{array}{r}\text { Detention } \\
\text { ponds }\end{array}$ & Precipitation & $\begin{array}{r}\text { Consistency } \\
\text { ratio }\end{array}$ \\
\hline Condition map & 0.300 & 0.233 & 0.233 & 0.167 & 0.067 & - & 0.012 \\
\hline Assessment map & 0.225 & 0.175 & 0.175 & 0.125 & 0.050 & 0.250 & 0.014 \\
\hline
\end{tabular}

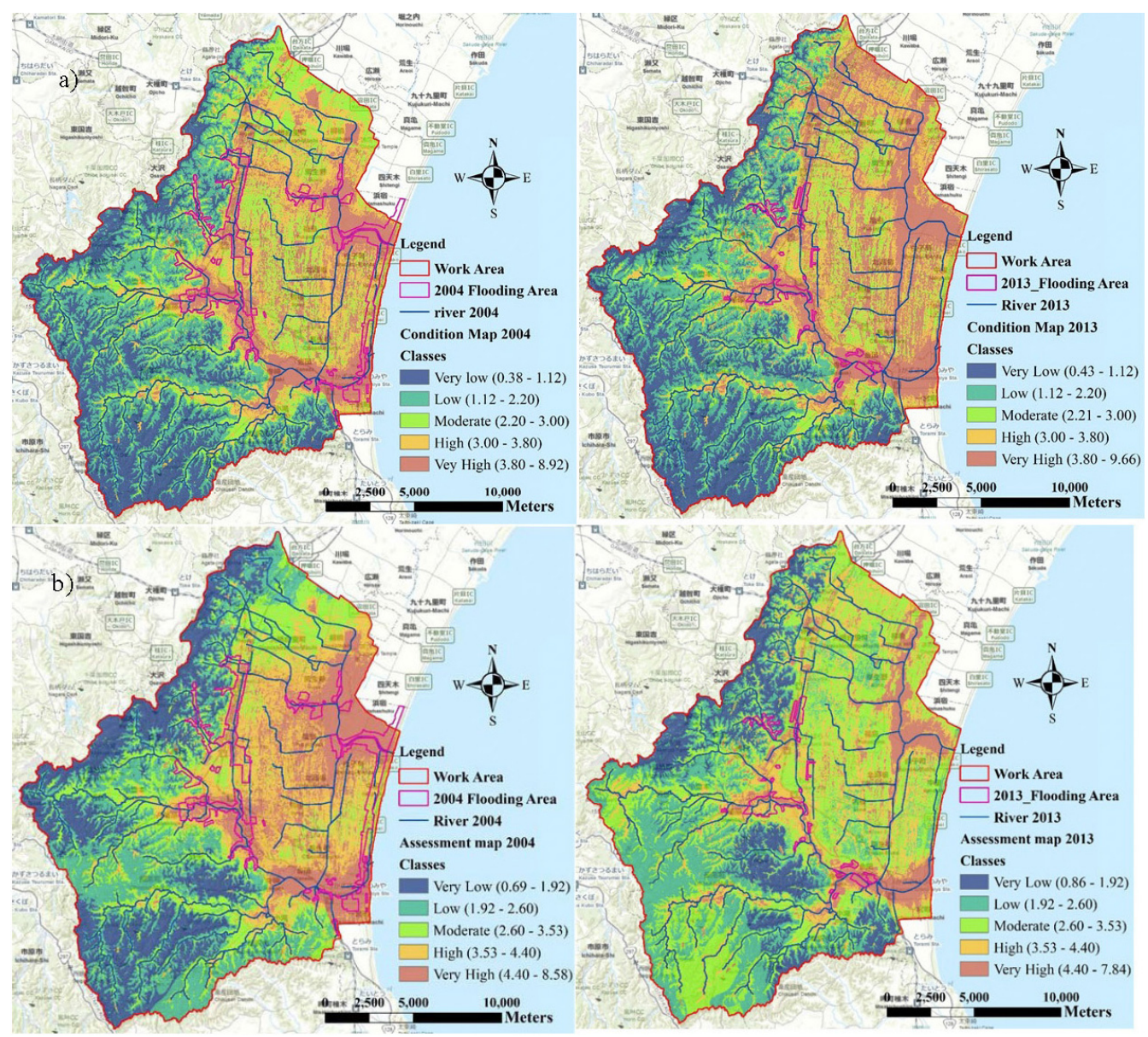

Figure 4. (a) Flood hazard condition map and (b) flood assessment map obtained by this study, for left (2004) and right (2013). The areas surrounded by pink line show the ones actually flooded (Chiba Prefecture, 2005, 2013).

and higher river density. The comparison between the actual flood areas reported by the local authorities (Chiba Prefecture, 2005, 2013) and the map constructed in this study showed that most of the flooded areas were located in the very high hazard potential area.

\section{Discussion and summary}

By comparing the results for three different periods, 1970, 2004 and 2013, the urban area enlarged significantly, the area effected by detention ponds became lager, while the change of the river system, the depression area and that of the elevation layer were small. For precipitation, it was difficult
Table 2. The areal percentage of each class for the condition and assessment maps.

\begin{tabular}{lrrrr}
\hline Class name & \multicolumn{2}{c}{ Condition map } & \multicolumn{2}{c}{ Assessment map } \\
\cline { 2 - 5 } & 2004 & 2013 & 2004 & 2013 \\
\hline Very low & $18.89 \%$ & $18.36 \%$ & $19.49 \%$ & $11.75 \%$ \\
Low & $20.53 \%$ & $20.44 \%$ & $20.48 \%$ & $22.21 \%$ \\
Moderate & $20.04 \%$ & $16.07 \%$ & $20.00 \%$ & $35.28 \%$ \\
High & $20.52 \%$ & $17.87 \%$ & $20.06 \%$ & $19.72 \%$ \\
Very High & $20.02 \%$ & $27.25 \%$ & $19.96 \%$ & $11.04 \%$ \\
\hline
\end{tabular}


to compare because of differences in the resolution of the data and the rather large spatial difference of precipitation patterns. From Table 2, it was found that the percentage of very high hazard potential was increased from year 2004 to 2013 for the condition map with slight decreases of the high and moderate potential classes. However, other classes did not show big changes. Due to the large difference of spatial patterns of precipitation between year 2004 and 2013, the change in the assessment map was difficult to compare.

The areas with highest flood potential are in the southeastern, the northeastern and the central parts of the study area. The land cover change may increase the flood hazard potential. Construction of flood hazard maps with different periods described in this paper can assist decision makers and planners to evaluate the study area with respect to the temporal and spatial changes of different factors. This study can be applied as an early stage assessment of the flooding problem. A flood model will be developed to simulate more detailed change of the flood hazard influenced by land subsidence.

Acknowledgements. We would like to express our sincere gratitude to the Keiyo Natural Gas Association (Japan), the National Natural Science Foundation of China (41401539), and Science Research Foundation for the Returned Overseas Chinese Scholars (State Education Ministry of China, (2015) No. 1098) for supporting this study. Residential maps provided by ZENRIN CO., LTD are used as the CSIS Joint Research (No. 524) using spatial data provided by Center for Spatial Information Science, The University of Tokyo.

\section{References}

Chen, H. L., Ito, Y., Sawamukai, M., and Tokunaga, T.: Flood hazard assessment in the Kujukuri Plain of Chiba Prefecture, Japan, based on GIS and multicriteria decision analysis, Nat. Hazards, 78, 105-120, 2015.

Chiba Prefecture: Flooding report in Chiba Prefecture, Chiba, 1212, 2005 (in Japanese).

Chiba Prefecture: Flooding report in Chiba Prefecture, Chiba, 1818, 2013 (in Japanese).

Doornkamp, J. C.: Coastal flooding, global warming and environmental management, J. Environ. Manage., 52, 327-333, 1998.

Environmental and Community Affairs Department: Chiba Prefecture, Leveling results in Chiba Prefecture, reference date: February 1970-1 January 2007, 2007 (in Japanese).

Hunt, A. and Watkiss, P.: Climate change impacts and adaptations in cities: A review of the literature, Climatic Change, 104, 13-49, 2011.

IPCC, Climate change 2013: The physical science basis, Cambridge, edited by: Stocker, T. F., Qin, D., Plattner, G. K., Tignor, M. M. B., Allen, S. K., Boschung, J., Nauels, A., Xia, Y., Bex, V., Midgley, P. M., Cambridge, Cambridge University Press, 659741, 2013.

Obanawa, H., Tokunaga, T., Rokugawa, S., Deguchi, T., and Nakamura, T.: Land subsidence at the Kujukuri Plain in Chiba Prefecture, Japan: Evaluation and monitoring environmental impacts, IAHS Publ., 339, 17-22, 2010.

Saaty, T. L.: The Analytic Hierarchy Process, Mc Graw Hill Company, New York, 1980. 